\title{
Shared Distance: The Poetry of Data in Collaborative GPS Visualisations
}

\author{
Jen Southern \\ Sociology Department \\ Lancaster University, \\ LA1 4YT, UK \\ j.a.southern@lancaster.ac.uk
}

\author{
Chris Speed \\ Edinburgh College of Art \\ University of Edinburgh, \\ Edinburgh EH3 9DF, UK \\ c.speed@ed.ac.uk
}

\section{INTRODUCTION}

Location based mobile applications are becoming increasingly popular and visualisation of GPS tracks increasingly familiar in TV programs such as 'Britain from Above' (2008). Networked locative technologies, such as GPS-enabled smart phones, can bring about a sense of presence at a distance or virtual proximity (Urry 2002) and consequently life in a city is made up of a complex set of flickering attentions to proximate and distant interactions (Elliot \& Urry 2010). This paper explores how the artists work Shared Distance by Southern and Speed makes fragile and flickering portraits of connected groups of people using GPS data.

\section{IMAGINATION AND DISTANCE}

Set in the context of the sociology of mobilities (Sheller \& Urry 2006), and mobile methods (Buscher, Urry, Witchger 2011) this paper asks how the increasingly popular visualizations of live GPS data are changing social and mobile experiences of place through an exploration of artists iPhone app Comob Net and installation Shared Distance 2013. Comob is a digital arts project that explores the potential for collaborative mapping with GPS technology. Comob was developed as a research tool to explore social and spatial relationships between people in motion. The App was developed by Jochen Ehnes and the backend work by Henrik Ekeus, whilst Southern and Speed explore the conceptual implications as well as deploy it through research workshops. In this paper we focus on how visualizations of collaborative GPS data from the app offer a new dimension to locative mapping facilitating a sense of distant connection that is both real and imagined (Soja 1996, Cresswell 2006).

\section{DATA PORTRAITS}

Shared Distance is an installed data visualisation from the Comob Net app that has been used by hundreds of people over the past 3 years, some simply trying it out, others using it to co-ordinate their movements for a particular event, and a few using it daily over several years. This app is not simply a way of finding friends, and accumulating points like apps such as Foursquare, it also helps to co-ordinate movements, keep in touch with distant loved ones, and to travel with others at a distance, thus intervening in social life.

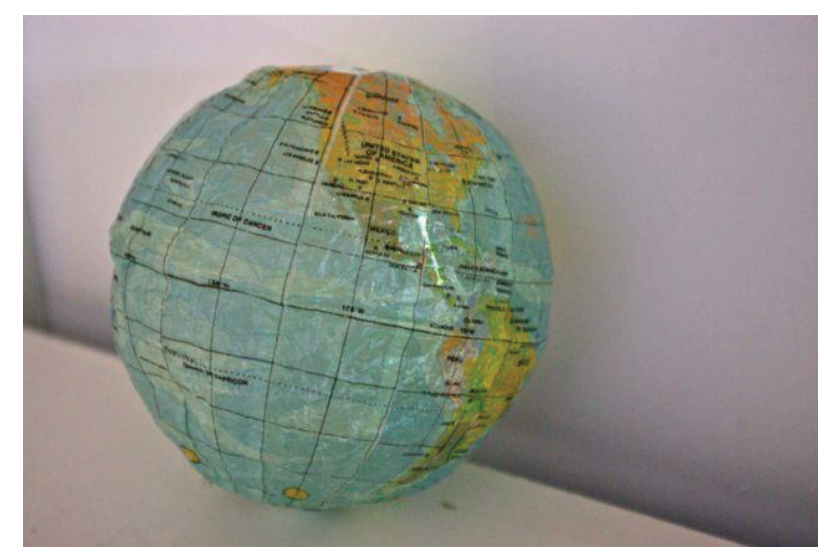

Figure 1: Shared Distance 1 (2013) Jen Southern \& Chris Speed

The data visualised here shows a delicate set of social choreographies, families who come and go but always meet back at the same location, a transport company that is continually on the move, lovers who keep in touch when they are away from home, and friends who co-ordinate their annual holiday party. It explores the real and imagined lives that their anonymised GPS traces evoke. In the Shared Distance installation GPS data of actions that have happened over weeks, months 
and years are replayed as abstracted animations, and projected on to evocative objects.

GPS is often thought of simply as a navigation aid for individual people or vehicles. This paper problematizes this idea by describing how the Comob Net app enacts complex relationships as part of a social assemblage of people, cities, animals, vehicles, satellites and networks. It explores how GPS is becoming embedded in social experiences and how new kinds of relationships are performatively co-created between people, places and technologies in a world that is increasingly on the move. Rather than the Google Maps ideal of making everything visible from everywhere in satellite and street view images the work suggests that all views are partial fragments through which proximate and distant interactions are entangled. In this sense GPS technology is extending the reach of action and vision at a distance, and is becoming part of the social choreography of everyday lives.

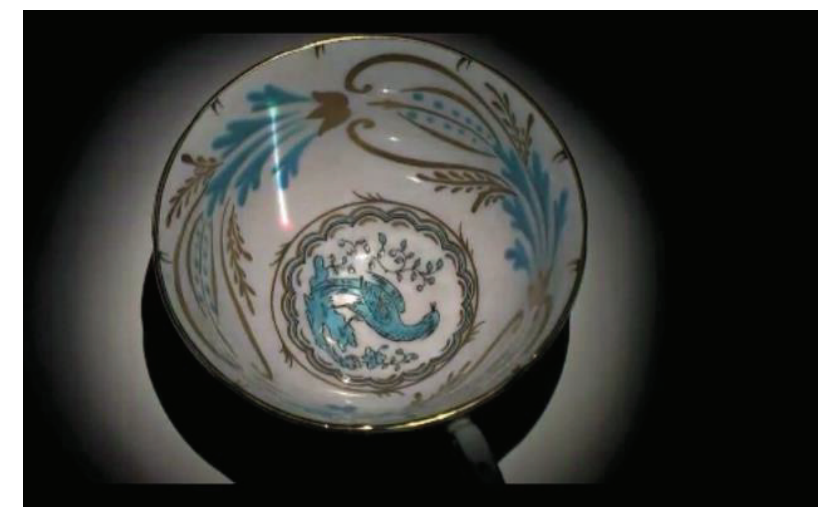

Figure 2: Shared Distance 2 (2013) Jen Southern \& Chris Speed

\section{REFERENCES}

Büscher, M., Urry, J. \& Witchger, K. (2011) Mobile Methods. Routledge, Abingdon

Cresswell, T. (2006) On the Move: Mobility in the Modern World. Routledge

Elliot, A. \& Urry, J. (2010) Mobile Lives. Routledge. New York and Abingdon

Sheller M, \& Urry J, (2006) The new mobilities paradigm. Environment and Planning A 38(2) $207-$ 226

Soja, E. W. (1996) Thirdspace. Malden (Mass.): Blackwell.

Urry, J. (2002). Mobility and proximity. Sociology, 36(2), 255-274. 